nhân không rung nhĩ, điện đồ ghi được tại tĩnh mạch phổi chủ yếu là các điện thế 1 pha, hai pha hoặc 3 pha, có các hoạt động điện thế hẹp khổng có sự phân tách rõ ràng với hoạt động điện từ nhĩ [6]. Theo tác giả Milad El Haddad (2015) cho thây, sau khi cô lập tĩnh mạch phổi thì ở bệnh nhân rung nhĩ vẫn còn điện đồ tại tĩnh mạch phổi, tuy nhiên hình dạng điện đồ đã có nhiều thay đổi: trước cô lập chủ yếu là điện đồ 3 pha, nhiều thành phần và điện đồ kép, còn sau cô lập tĩnh mạch phổi thì điện đồ chủ yếu đơn giản và ít thành phần hơn[7].

\section{KẾT LUẬN}

Kết quả nghiên cứu cho thấy,cácbệnh nhân rung nhĩ kịch phát đềucó điện đồ tại ít nhất một tĩnh mạch phổi (chiếm 100\%), trong đó $80 \%$ bệnh nhân có cả 4 tĩnh mạch phổi có điện đồ.Khoảng thời gian dẫn truyền nhĩ - tĩnh mạch phổi (khoảng A-PV) tối đa và trung bình ở tî̃nh mạch phổi trên trái là dài nhất $(67,00 \pm 9,72 \mathrm{~ms}$ và $56,65 \pm 8,52 \mathrm{~ms}$, tương ứng). Hình dạng điện đồ tĩnh mạch phổi thường gặp là điện đồ nhiểu thành phần $(31,6 \% \pm 8,7 \%)$. Điện đồ kép chiếm tỷ lệ $5,8 \% \pm 5,9 \%$, trong đóhình dạng điện đồ kép gặp nhiều nhất ở tĩnh mạch phổi trên trái $(11,9 \% \pm 6,8 \%)$.

\section{TÀI LIÊU THAM KHẢO}

1. Chugh S.S., Havmoeller R., Narayanan K., et al (2014). Worldwide Epidemiology of Atrial Fibrillation: A Global Burden of Disease 2010 Study. Circulation, 129(8), 837-847.

2. Snoer A.H., Ellemann $K_{\text {., }} \&$ Wienecke $T$. (2014). High Prevalence of Paroxysmal Atrial Fibrillation in A Selected Population of Patients with Stroke and Transient Ischemic Attack, 5.

3. Moreira W., Manusama R., Timmermans $\mathbf{C}_{\text {. }}$ et al (2008). Long-term follow-up after cryothermic ostial pulmonary vein isolation in paroxysmal atrial fibrillation. Journal of the American College of Cardiology, 51(8), 850-855.

4. Tada H., Oral H., Greenstein R., et al (2002) Differentiation of atrial and pulmonary vein potentials recorded circumferentially within pulmonary veins. Journal of cardiovascular electrophysiology, 13(2), 118-123.

5. Haïssaguerre M., Shah D.C., Jaïs $P_{\text {., }}$ et al (2000). Electrophysiological breakthroughs from the left atrium to the pulmonary veins. Circulation, 102(20), 2463-2465.

6. Hertervig E., Kongstad O., Ljungstrom E., et al (2008). Pulmonary vein potentials in patients with and without atrial fibrillation. Europace, 10(6), 692-697.

7. El Haddad M., Houben R., Berte B., et al (2015). Bipolar electrograms characteristics at the left atrial-pulmonary vein junction: Toward a new algorithm for automated verification of pulmonary vein isolation. Heart Rhythm, 12(1), 21-31.

8. Haissaguerre M., Jaïs P., Shah D.C., et al (1998). Spontaneous initiation of atrial fibrillation by ectopic beats originating in the pulmonary veins. New England Journal of Medicine, 339(10), 659-666.

\title{
ĐĂC ĐIỂM LÂM SÀNG VÀ TÌNH HÌNH ĐỀ KHÁNG KHÁNG SINH TRÊN BỆNH NHÂN CHỐC TẠI BỆNH VIỆN DA LIỄU THÀNH PHỐ CẦN THO' NĂM 2020
}

\author{
Trần Nguyễn Anh Thu*, Huỳnh Văn Bá*, \\ Nguyễn Thị Thùy Trang*, Lạc Thị Kim Ngân*, Phạm Thanh Thảo*
}

\section{TÓM TẮT}

Mục tiêu: Mô tả đặc điểm lâm sàng và tình trạng kháng thuốc của các vì khuẩn nhiếm trên bệnh nhân chốc đến khám tại bệnh viện Da Liễu TP. Cần Thơ từ 06/2020 - 12/2020. Đối tượng và phương pháp: Mô tả cắt ngang trên mẫu là 55 bệnh nhân, được lấy bệnh phẩm sang thương trên da, nuôi cấy và̀ làm kháng sinh đồ. Kết quả: 35 trường hợp bệnh nhân bị chốc có kết quả cây vi khuẩn dương tính $(63,6 \%)$.

*Trường Đại học Y Dược Cần Thơ Chịu trách nhiệm chính: Trần Nguyễn Anh Thư Email: trannguyenanhthu.y39@gmail.com Ngày nhận bài: 15/6/2021

Ngày phản biện khoa học: 14/7/2021

Ngày duyệt bài: 15/8/2021
Trong số này, chốc không bóng nước là $61,8 \%$, chốc bóng nước là $25,5 \%$ và chốc loét là $12,7 \%$. Đa số vi khuẩn phân lập được là S.aureus (93,8\%). Tỉ lệ S.aureus kháng với penicillin và erythromycin là $100 \%$, kháng với amoxicillin/acid clavulanic là $93,5 \%$, còn nhạy với cefuroxime, oxacillin, tetracyclin, ciprofloxacin, levofloxacin, linezolid và vancomycin, có 2 trường hớp kháng với vancomycin thuộc thể chốc loét. Tỉ lệ chủng tụ câu vàng kháng methicillin (MRSA) được phát hiện trong nghiên cứu là $87,1 \%$. Và cả 3 ca cây ra S.pyogenes (chiếm 8,6\%) vẫn còn nhay với penicillin. Kết luận: Chốc không bóng nước là thể bệnh thường găp nhất trên lâm sàng. Tác nhân gây bênh chủ yếu làs.aureus, gần nhữ kháng toàn bộ với penicillin, erythromycin, và vẫn còn nhay cao với oxacillin, cefuroxime và vancomycin. Tư khóa: Chốc, kháng kháng sinh, S.aureus, S. pyogenes. 


\section{SUMMARY \\ THE CLINICAL FEATURES AND THE ANTIBIOTIC RESISTANCE OF BACTERIA CAUSING IMPETIGO AT CAN THO HOSPITAL CITY OF DERMATO- VENEREOLOGY}

Objective: To demonstrate clinical features and antibiotic resistance of bacteria causing impetigo in patients at Can Tho city Hospital of DermatoVenereology from June 2020 to December 2020. Materials and methods: A descriptive crosssectional study of 55 patients, clinical characteristics of patients with impetigo were recorded. Bacteria from impetigo pus were isolated. Antiobiogram examination with multiple antibiotics was performed. Results: 35 $(63,6 \%)$ patients with impetigo had positive bacteriological cultures. Regarding clinical features, non-bullous impetigo was $61,8 \%$, bullous impetigo was $25,5 \%$ and ecthyma was $12,7 \%$. On the examination of biology features, S. aureus was $93.8 \%$ of cases. Penicillin-resistant S.aureus and erythromycin-resistant S.aureus was 100\%; amoxicillin/acid clavulanic-resistant S. aureus was 93,5\%; bacteria were sensitive to cefuroxime, oxacillin, tetracyclin, ciprofloxacin, levofloxacin, linezolid and vancomycin; the 3 case vancomycinresistant was ecthyma. Methicillin-Resistant Staphylococcus aureus (MRSA) was $87,1 \%$.And 2 S.pyogenes cases $(8,6 \%)$ remained susceptible to penicillin. Conclusion: Non-bullous impetigo was the most common clinical feature. The main bacterium is S.aureus, which was completely resistant to penicillin and erythromycin. On the other hand, it was still highly sensitive to oxacillin,cefuroxime, and vancomycin.

Key words: Impetigo, antiobiotics resistance, S.aureus, S. pyogenes.

\section{I. ĐẠT VẤN ĐỀ}

Chốc là bệnh nhiễm trùng da nông rất thường găp trong chuyên ngành Da Liễu Tại Khoa Khám Bệnh của bệnh viện Da Liễu TP. Hồ Chí Minh, trong 5 năm (2008 - 2012), mỗi năm có khoảng 2000-3000 trẻ em được chẩn đoán bệnh chốc. Nếu không điều trị hoặc điều trị khổng đúng bệnh sẽ lan rộng, có thể gây ra các biến chứng nguy hiểm. Do đó, chẩn đoán và điều trị sớm, đúng thuốc, đúng liều là một yêu cầu rất cần thiết. Theo y văn, tại các nước đang phát triển, S.pyogenes là tác nhân gây bệnh chủ yếu [5]. Và việc điều trị hiệu quả là dựa vào tình trạng kháng thuốc của tác nhân gây bệnh tại thời điểm nhất định. Tuy nhiên, ở Việt Nam nói chung và Cần Thơ nói riêng trong 5 năm gần đây chưa có nghiên cứu nào khảo sát tác nhân gây bệnh chốc trẻ em cũng như sự kháng thuốc của các tác nhân này. Xuất phát từ những lý do trên, chúng tôithực hiên đề tài "Đặc điểm lâm sàng và tình hình đề kháng kháng sinh của vi khuẩn nhiễm trên bệnh nhân chốc tại Bệnh viện Da liễu thành phố Cần Thơ năm 2020" với mục tieu:

- Mô tả đặc điểm lâm sàng của bệnh nhân chốc điều trị tại Bệnh viện Da liếu Thành phố Cần Thơ năm 2020.

- Xác định tỷ lệ nhiễm và đề kháng với kháng sinh của các loại vi khuẩn trên bệnh nhân chốc điều trị tại Bệnh viện Da Liễu Thành phố Cần Thơ năm 2020.'

\section{II. ĐỐI TƯỢNG VÀ PHƯƠNG PHÁP NGHIÊN CỨU}

1. Đối tượng nghiên cứu. Tất cả bệnh nhân được chẩn đoán chốc đến khám và điều trị tại Bệnh viện Da liễu Thành phố Cần Thơ năm 2020.

Tiêu chuẩn chọn mẫu: Chọn mẫu nghiên cứu là những bệnh nhân được chẩn đoán bệnh chốc điều trị tại Bệnh viện Da liễu Thành Phố Cần Thơ.

Tiêu chuẩn chẩn đoán bệnh chốc bao gồm:

- Thương tổn: bóng nước, mụn nước hóa mủ nhanh, đóng mày. Mày đóng mày màu vàng nâu hoặc màu vàng mật ong.

- Vị trí: miệng, mũi, thân mình, tay chân.

- Cơ năng: ngứa, đau, rát.

- Toàn thân: sốt hoặc hạch viêm.

- Nhuộm Gram/nuôi cây

\section{Tiêu chuấn loai trừ}

- Bệnh nhân có bệnh lý toàn thân nặng (suy gan, suy thận) hoặc chưa ổn định.

- Bệnh nhân không đồng ý tham gia nghiên cứu

2. Thiêt kế nghiên cứu. Mô tả cắt ngang

Cỡ mẫu: $n=55$

3. Phương pháp tiến hành. Khám lâm sàng và làm bệnh án, thu thập số liệu.

\section{Chẩn đoán chốc trên lâm sàng dựa vào} các đặc điểm:

Chốc bóng nước: nhiêu mụn nước tiến triển nhanh thành bóng nước chùng, nông, kích thước khoảng $1-2 \mathrm{~cm}$, chứa dịch vàng trong hoặc đục dần tạo thành bóng mủ. Bóng nước võ nhanh trong 1-2 ngày để lại những vết trợt, đóng mài, giới hạn rõ. Mài thường mỏng, có màu vàng hay nâu nhạt, vết trợt có viên thượng bì xung quanh. Có thể gặp ở bất cứ vị trí nào trên cơ thể, nhưng thường ở mặt, quanh mũi, miệng, thân mình.

- Chốc không bóng nước: nhiêu mụn nước hay mụn mủ, vỡ nhanh, đóng mài vàng mật ong với viền mủ rất đặc trưng, có mảng hồng ban viêm đỏ xung quanh đường kính khoảng $2 \mathrm{~cm}$. Thương tổn tiến triển lan rộng nhanh ra xung quanh tạo sang thương vệ tinh. Vị trí thường gặp ở mặt, nhất là quanh mũi, và ở tay, chân (sau chân thương).

- Chốc loét bắt đầu với những mụn nước hoặc mụn nước - mụn mủ, sau đó tiến triển lan rộng, 
sâu hơn, đóng mài dày trong vài ngày. Khi mài tróc ra sẽ thây vết loét nông, hình đĩa, đáy màu đỏ và bờ nhô cao. Thường xảy ra ở 2 chi dưới, nhất là cẳng chân và lưng bàn chân.

Cấy vi khuẩn: bệnh nhân được lấy bệnh phẩm bằng tăm bông vô trùng phết ở trung tâm thương tổn, cho vào ống nghiệm có chứa môi trường chuyên chở và sau đó cấy trực tiếp lên môi trường thạch máu, tại phòng xét nghiệm khuẩn của Bệnh viện trường Đại học Y Dược Cần Thơ.

Làm kháng sinh đồ: theo Qui trình thao tác chuẩn về thử nghiệm tính nhạy cảm kháng sinh (CLSI) [2].

4. Xử lý số liệu: Số liệu được nhập, phân tích và xử lý bằng phần mềm SPSS 18.0.

\section{KẾT QUẢ NGHIÊN CỨU}

Trong khoảng thời gian 6 tháng từ tháng 06/2020 đến tháng 12/2020 chúng tôi thu thập được 55 bệnh nhân có thương tổn chốc thỏa mãn tiêu chuẩn chọn bệnh ban đầu, trong đó kết quả cấy dương tính 35 bệnh nhân (61,8\%).

1. Một số đặc điểm dịch tễ của bệnh chốc

Tuổi và giới. Tuổi nhỏ nhất là 10 tháng, lớn nhất là 11 tuổi, trung bình 3,67 $\pm 3,12$. Tập trung nhiều ở nhóm tuổi 2-6 chiếm 58,2\% (Bảng 1). Nam chiếm tỷ lệ cao hơn nữ (Bảng 2)

Bảng 1. Tý lẹ bệnh nhân chốc theo tuổi

\begin{tabular}{|c|c|c|}
\hline Nhóm tuối & Tân số (n) & Tỷ lệ (\%) \\
\hline$<2$ & 14 & $25,5(\%)$ \\
\hline $2-6$ & 32 & $58,2(\%)$ \\
\hline$\geq 6$ & 9 & $16,4(\%)$ \\
\hline Tổng cộng & 55 & $100(\%)$ \\
\hline TB \pm ĐLC & \multicolumn{2}{|c|}{$3,67 \pm 3,12$} \\
\hline Bảng 2. $T \dot{y} \mid$ & ệnh nhân chá & heo giới tính \\
\hline Giới tính & Tân số (n) & Tỷ lệ (\%) \\
\hline Nam & 37 & $67,3(\%)$ \\
\hline Nữ & 18 & $32,7(\%)$ \\
\hline Tống cộng & 55 & $100(\%)$ \\
\hline
\end{tabular}

2. Đặc điếm lâm sàng của bênh nhân chốc

Bảng 3. Tỷ lệ bệnh nhân chốc theo thể lâm sàng

\begin{tabular}{|c|c|c|}
\hline Thể lâm sàng & $\begin{array}{c}\text { Tân số } \\
(\mathbf{n})\end{array}$ & $\begin{array}{c}\text { Tỷ lệ } \\
(\%)\end{array}$ \\
\hline Chốc không bóng nước & 34 & $61,8(\%)$ \\
\hline Chốc bóng nước & 14 & $25,5(\%)$ \\
\hline Chốc loét & 7 & $12,7(\%)$ \\
\hline Tống cộng & $\mathbf{5 5}$ & $\mathbf{1 0 0} \% \mathbf{\%}$ \\
\hline
\end{tabular}

Nhận xét: thể lâm sàng chốc không bóng nước chiếm tỷ lệ cao nhất là $61,8 \%$.

Bảng 4. Mối liên liên quan giữa nơi cư trú theo thể lâm sàng

\begin{tabular}{|c|c|c|c|c|}
\hline \multirow{2}{*}{ Thể lâm sàng } & \multicolumn{2}{|c|}{ Nơi cư trú } & \multirow[b]{2}{*}{ Tổng } & \multirow[b]{2}{*}{ p } \\
\hline & Thành thi & Nông thôn & & \\
\hline Chốc không bóng nước & $13(39,45 \%)$ & $20(60,6 \%)$ & 33 & \multirow{4}{*}{$p=0,021$} \\
\hline Chốc bóng nước & $0(\%)$ & $14(100 \%)$ & 14 & \\
\hline Chốc loét & $3(37,5 \%)$ & $5(62,5 \%)$ & 8 & \\
\hline Tống & $26(29,1 \%)$ & $39(70,9 \%)$ & 55 & \\
\hline
\end{tabular}

Nhận xét: hầu hết các thế bệnh đều có nơi cư trú ở nông thôn chiếm tỷ lệ cao hơn thành thị trong đó có chốc bóng nước là $100 \%$ đều ở nông thôn, sự khác biệt này có ý nghĩa thống kê với $\mathrm{p}=0,021$.

3. Tình trạng kháng thuốc của vi khuẩn gây bệnh chổc

Bảng 5. Tỷ lệ tác nhân vi khuẩn gây bệnh chốc

\begin{tabular}{|c|c|c|}
\hline Tác nhần & Tân số (n) & Tỷ lệ \% \\
\hline Staphylococcus aureus & 31 & $93,8(\%)$ \\
\hline Streptococcus pyogenes & 3 & $8,6(\%)$ \\
\hline Vi khuấn khác & 1 & $2,9(\%)$ \\
\hline Tống & $\mathbf{3 5}$ & $\mathbf{1 0 0}(\%)$ \\
\hline
\end{tabular}

*1 ca Escherichia coli

Nhận xét: Đa số tác nhân gây bệnh là Staphylococcus aureus chiếm 93,8\% (Bảng 5).

S. aureus kháng với nhiêu loại kháng sinh trong đó $100 \%$ kháng với clindamycin, penicillin, erythromycin, trimetroprim-sufamethoxazol, kế đến là amoxicillin/acid clavulanic và ceftriaxon $(93,5 \%)$, cefuroxime và oxacillin là $87,1 \%$, cefixim chiếm $83,9 \%$, tiếp theo lần lượt là tetracylin $(58,1 \%)$, ciprofloxacin $(35,5 \%)$, levofloxacin $(25,8 \%)$ và cuối cùng là vancomycin
(6,5\%) (Bảng 6).

Bảng 6. Kết quả kháng sinh đồ của 35 trường hợp S. aureus

\begin{tabular}{|c|c|c|c|c|}
\hline \multirow{2}{*}{$\begin{array}{c}\text { Loại kháng } \\
\text { sinh }\end{array}$} & $\begin{array}{c}\text { Kháng } \\
\text { Số ca } \\
\text { (n) }\end{array}$ & $\begin{array}{c}\text { Tý lệ } \\
\text { (\%) }\end{array}$ & $\begin{array}{c}\text { Số ca } \\
\text { (n) }\end{array}$ & $\begin{array}{c}\text { Tỷ lệ } \\
(\mathbf{\%})\end{array}$ \\
\hline Clindamycin & 31 & 100 & 0 & 0 \\
\hline Penicillin & 31 & 100 & 0 & 0 \\
\hline Erythromycin & 31 & 100 & 0 & 0 \\
\hline Trimetroprim & 31 & 100 & 0 & 0 \\
\hline $\begin{array}{c}\text { Amoxicillin/acid } \\
\text { clavulanic }\end{array}$ & 29 & 93,5 & 2 & 6,5 \\
\hline Ceftriaxon & 29 & 93,5 & 2 & 6,5 \\
\hline Cefuroxim & 27 & 87,1 & 4 & 12,9 \\
\hline Oxacillin & 27 & 87,1 & 4 & 12,9 \\
\hline Cefixim & 26 & 83,9 & 5 & 16,1 \\
\hline Tetracylin & 18 & 58,1 & 13 & 41,9 \\
\hline Ciprofloxacin & 11 & 35,5 & 20 & 64,5 \\
\hline Levofloxacin & 8 & 25,8 & 23 & 74,2 \\
\hline
\end{tabular}


\begin{tabular}{|l|l|l|l|l|} 
Vancomycin & 2 & 6,5 & 29 & 93,5 \\
\hline
\end{tabular}

Bảng 7. Tỷ lệ đề kháng một số kháng sinh nhóm $\beta$-lactams của chủng MRSA so với chủng MSSA

\begin{tabular}{|c|c|c|}
\hline \multirow{2}{*}{ Kháng sinh } & \multicolumn{2}{|c|}{ Tác nhân gây bệnh } \\
\cline { 2 - 3 } & MRSA & MSSA \\
\hline penicillin & $100 \%$ & $100 \%$ \\
\hline cefuroxim & $88,9 \%$ & $75 \%$ \\
\hline tetracylin & $55,6 \%$ & $25 \%$ \\
\hline
\end{tabular}

Cả 2 chủng MRSA và MSSA gân như kháng tất cả với penicillin. Chủng MRSA có tỷ lệ đề kháng các kháng sinh nhóm $\beta$-lactams khác penicillin cao hơn chủng MSSA (Bảng 7).

Nhìn chung, tỷ lệ đề kháng của MRSA và MSSA đối với erythromycin là rất cao chiếm $100 \%$, chi tiết hơn ta thây chủng MRSA kháng ciprofloxacin (33,3\%), levofloxacin (22,2\%) và vancomycin $(7,4 \%)$ cao hơn chủng MSSA, hơn nữa là chủng MSSA chưa ghi nhận kháng với levofloxacin và vancomycin (Bảng 8 ).

Bảng 8. Tỷ lệ đề kháng một số kháng sinh tiêu biểu không phải nhóm $\beta$-lactams của chủng MRSA so với chüng MSSA

\begin{tabular}{|c|c|c|}
\hline \multirow{2}{*}{ Kháng sinh } & \multicolumn{2}{|c|}{ Tác nhân gây bệnh } \\
\cline { 2 - 3 } & MRSA & MSSA \\
\hline Erythromycin & $100 \%$ & $100 \%$ \\
\hline Ciprofloxacin & $33,3 \%$ & $25 \%$ \\
\hline Levofloxacin & $22,2 \%$ & $0 \%$ \\
\hline Vancomycin & $7,4 \%$ & $0 \%$ \\
\hline
\end{tabular}

\section{BÀN LUẦN}

1. Đặc điểm dịch tễ mẫu nghiên cứu. Theo nghiên cứu của chúng tôi tuổi nhỏ nhất là 10 tháng, lớn nhất là 11tuổi, trung bình là 3,67 $\pm 3,12$. Tập trung nhiêu nhất ở nhóm tuổi 2-6 $(58,2 \%)$ (bảng 1$)$. Về giới, nam $(67,3 \%)$ chiếm tỷ lệ cao hơn nữ (32,7\%) (bảng 2 ). Kết quả này cũng phù hợp với các tác giả Mai Thị Liên (2016) [1].

2. Đặc điểm lâm sàng của mẫu nghiên cứu. Theo kết quả nghiên cứu của chúng tôi về thể lâm sàng, chốc không bóng nước chiếm tỷ lệ cao nhất là $61,8 \%$ (bảng 3). Theo y văn, tỷ lệ chốc không bóng nước là 70\% [5]. So sánh với các nghiên cứu của các tác giả Cole $C$ và cộng sự (2007), Abdullash SH và cộng sự (2015) cho thây tỷ lệ này gân như xấp xỉ lân lượt là $70 \%$ và $66,7 \%[4]$.

Về nơi cư trú, theo nghiên cứu của chúng tôi, tỷ lệ nơi cử trú ở nông thôn (70,9\%) chiếm tỷ lệ cao hơn so với thành thị $(29,1 \%)$, hâuu hết các thể bệnh đều có nơi cư trú ở nông thôn chiếm tỷ lệ cao hơn thành thị trong đó có chốc bóng nước là $100 \%$ đều ở nông thôn, sự khác biệt này có ý nghĩa thống kê $(p=0,021)$. Kết quả này tương tự với tác giả Mai Thị Liên (2016) là tỷ lệ bệnh nhân mắc bệnh chốc ở thành thị là 44,29\% thấp hơn so với ở nông thôn- miên núi là 55,71\% [1].

3. Tác nhân gây bệnh chốc. Theo y văn, tại các nước công nghiệp, nguyên nhân của chốc không bóng nước thường do $\mathrm{S}$. aureus, còn tại các nước đang phát triển thì $S$. pyogenes vẫn là tác nhân thường gặp [5]. Tuy nhiên, theo kết quả nghiên cứu của chúng tôi, S.aureus là tác nhân gây bệnh chủ yếu trong chốc nói chung $(93,8 \%)$, và cả trong thể lâm sàng chốc không bóng nước nói riêng, chỉ một số ít do S.pyogenes $(2,9 \%)$ (bảng 5$)$. Kết quả nghiên cứu này phù hợp với nghiên cứu của tác giả Kumar $R$, và cộng sự được thực hiện tại bệnhviện Nhi ở Ấn Độ (2002) với tỷ lệ cấy S.pyogenes trong bệnh chốc ở trẻ em là 2,6\% (2/75 mẫu bệnh phẩm lấy từ thương tổn da) [6].

\section{Tình hình kháng thuốc của vi khuẩn nhiễm trên bệnh nhân chốc}

S. aureus. Theo kết quả nghiên cứu của chúng tôi, S. aureus kháng với nhiêu loại kháng sinh trong đó $100 \%$ kháng với clindamycin, penicillin, erythromycin, trimetroprim, kế đến là amoxicillin/acid clavulanic và ceftriaxon $(93,5 \%)$, cefuroxime và oxacillin là $87,1 \%$, cefixim chiếm $83,9 \%$, tiếp theo lân lượt là tetracylin $(58,1 \%)$, ciprofloxacin $(35,5 \%)$, levofloxacin $(25,8 \%)$ và cuối cùng thâp nhất là vancomycin $(6,5 \%)$. Kết quả này khác với nghiên cứu của Liu Y (2009) và Trân Nguyên Ánh Tú (2016) với tỷ lệ đề kháng penicillin thì gân như tương đồng, nhưng tỷ lê đề kháng với các loại kháng sinh khác thì cho thấy thấp hơn, nguyên nhân có thể là do sự khác biệt về thời điểm nghiên cứu cách xa nhau, tình trạng kháng thuốc đã tăng dân theo thời gian [3], [7].

Theo kết quả nghiên cứu của chúng tôi cho thấy đối với các kháng sinh thuộc nhóm $\beta$ lactams, ngoại trừ tỷ lệ đề kháng đối với penicillin của cả 2 chủng đêu rất cao (100\%), còn lại chủng MRSA có tỷ lệ đề kháng với các kháng sinh thuộc nhóm $\beta$-lactams khác cao hơn chủng MSSA. Tương tự, khi so sánh tỷ lệ đề kháng giữa MRSA và MSSA với một số kháng sinh tiêu biểu không phải $\beta$-lactams cũng cho kết quả MRSA có tỷ lệ kháng cao hơn. Kết quả này cũng tuơng tự với nghiên cứu của Trân Nguyên Ánh Tú (2016) [3].

S. pyogenes. Theo kết quả nghiên cứu của chúng tôi, cả 3 ca cấy vi khuẩn là Streptococcus pyogenes đều kháng với tetracylin, 2 ca kháng với erythromycin, 1 ca kháng với clindamycin không có ca nào kháng với penicillin. Kết quả này phù hợp với nghiên cứu của Richter (2015) 
không có trường hợp nào S. pyogenes kháng với penicillin [8].

\section{KẾT LUÂN}

Bệnh nhân bi bênh chốc trong mẫu nghiên cứu chủ yếu là chốc không bóng nước, với tỷ lệ $61,8 \%$, kế đến là chốc loét $25,5 \%$ và chốc bóng nước 8,6\%.

Tác nhân gây bệnh chủ yếu là $S$. aureus với tỷ lệ là $63,6 \%$ trong các trường hợp cây dương tính.

Tình trạng đề kháng với kháng sin penicillin của $\mathrm{S}$. aureus là rất cao $(98,5 \%)$, kế đến là erythromycin (81,5\%), clindamycin $(69,2 \%)$. Tuy nhiên, vi trùng này vấn còn nhạy cao với oxacillin $(61,8 \%)$, cefuroxime $(83,1 \%)$ và tỷ lệ MRSA là $13,8 \%$. Riêng 2 trường hợp $S$. pyogenes đều nhạy cảm với penicillin.

\section{TÀI LIỆ THAM KHẢO}

1. Mai Thị Liên (2016), "Đă̆c điểm lâm sàng, yễu tố liên quan và hiệu quả điều trị bệnh chốc bằng cefixim kết hợp với fucidin", Luận văn thạc sĩ y hơc, Trường đại học Y Hà Nội, Hà Nội,

2. Đố Thị Thúy Nga (2011), "Tiêu chuấn đọc kết quả kháng sinh đồ và MIC", Qui trình thao tác chuẩn về thử nghiệm tính nhạy cám kháng sinh (21),
3. Trân Nguyên Ánh Tú (2016), "Tình trạng kháng thuốc in vitro của Staphyloccocus aureus và Streptococcus pyogennes gây bênh chốc ở trẻ em đến khám tại Bệnh viện Da liễu thành phố Hồ Chí Minh", Tạp chí Y học Thành Phố Hồ Chí Minh, 20(2), tr.63-69.

4. Cole C. \& Gazewood J. (2007), "Diagnosis and treatment of impetigo ", Am Fam Physician 75(6), pp.859-864.

5. James G.H. Dinulos (2020), "Impetigo", Habif's Clinical Dermatology: A Color Guide in Diagnosis and Therapy, Elsevier, pp. 331-340.

6. Vohra $H$ Kumar $R$, Chakraborty $A$, et a (2009), "Epidemiology of group A streptococcal pharyngitis \&impetigo: a cross-sectional \& follow up study in a ruralcommunity of northern India", The Indian journal of medicalresearch,130(6), pp. 765-771.

7. Kong $F$ Liu $Y$, Zhang $X$, et al (2009), "Antimicrobial susceptibility of Staphylococcus aureus isolated from children with impetigo in China from 2003 to 2007 shows communityassociated methicillin-resistant Staphylococcus aureus to be uncommon and heterogeneous", The British journal of dermatology, 161(6), pp. 1347-1350.

8. Heilmann KP Richter SS, Beekmann SS (2015), "Macrolide-resistant Streptococcus pyogenes in the UnitedStates, 2012-2013", Clinical Infection Diseases,41(1), pp. 599 - 608.

\section{KẾT QUẢ SớM PHẪU THUÂT CẮT U MÔ ĐỆM (GIST) DẠ DÀY TẠI KHOA NGOẠI - BÊ̂NH VIỆN BẠCH MAI}

\section{Lun Panha ${ }^{1}$, Trần Quế Sơnn ${ }^{1,2}$, Trần Hiếu Học ${ }^{1,2}$}

\section{TÓM TẮT}

Mục tiêu: mô tả một số đặc điểm lâm sàng, cận lâm sả̉ng và kết quả phâ̂u thuât u mô đêm cứa da dày. Đối tượng và phương pháp nghiên cứu: mổ tả loạt ca bểnh, những trường hợp u mô đệm của da dày được phẫu thuật tại bệnh viện Bạch Mai từ 2016 đên 2019. Kết quả: 50 bênh nhẩn với tuổi trung bình $56,3 \pm 12,6$ và tỉ lệ nam/nữ là 0,79 . Đau bụng là triệu chứng thường gặp $(94 \%)$, nội soi thây có loét trên u $52 \%$ và vị trí u chủ yếu ở hang vị và thân vị $(74 \%)$; cắt lớp vi tính thấy kích thước u $9,2 \pm 9,0 \mathrm{~cm}$, bờ đều $88 \%$, ngấm thuốc manh $72 \%$; hai dâuu ân CD117 và CD 34 thấy $100 \%$. Cắt da dày hình chêm là kỹ thuật dùng nhiêuu nhất $76 \%$; thời gian trung tiện $1,9 \pm 0,7$ ngày, rút sonde dạ dày $2,5 \pm 1,3$ ngày, cho ăn trở lại $3,2 \pm 1,2$ ngày, nằm viện sau mổ trung bình 6,2 ngày. Tai biến chảy máu trong mổ $2(4,0 \%)$, biến chứng

\footnotetext{
${ }^{1}$ Trường Đại học Y Hà Nội

${ }^{2}$ Khoa Ngoại bệnh viện Bạch mai

Chịu trách nhiệm chính: Trần Hiếu Học.

Email: hieuhoc1305@gmail.com

Ngày nhận bài: 26/6/2021

Ngày phản biện khoa học: 30/7/2021

Ngày duyệt bài: 19/8/2021
}

nhiễm trùng vết mổ 4 (8,0\%). Kết luận: Chẩn đoán bệnh chủ yếu dựa vào nội șoi, chẩn đoán hình ảnh và xác định bằng hóa mô miển dịch. Phẫu thuật có kết quả sớm tốt, song cần theo dõi lâu dài thêm.

Tư khóa: U mô đệm đường tiêu hóa, dạ dày, phẫu thuật.

\section{SUMMARY}

\section{EARLY RESULTS OF SUGICAL TREAMENT OF GASTROINTESTINAL STROMAL TUMOR LOCALIZED IN THE STOMACH AT SURGERY, BACH MAI HOSPITAL}

Objectives: To describe some clinical, paraclinical features and surgical results of this disease. Material and methods: A descriptive study of the case series of GIST localized in the stomach operated at Bach Mai hospital from 2016 to 2019. Results: There was 50 patients with mean age $56.3 \pm 12.6$ and male/female ratio of 0,79 . The abdominal pain was common symptom (94\%), the endoscopy showed mucosal ulceration $52 \%$ and tumor locations were primarily at body and pyloric antrum (74\%); computed tomography showed the tumor size of $9.2 \pm 9.0 \mathrm{~cm}$, regular margins $88 \%$, two immune markers CD117 and $C D 34$ were present in $100 \%$. The wedge gastrectomy was most commonly used technique 